\title{
Fabrication of Ocular Prosthesis for Compromised Orbits in Demotivated Victims of Domestic Violence - A Case Report
}

\author{
Dr Subhash Sonkesriya ${ }^{1,}$ Dr Rahul Vishnoi BDS, (MDS) ${ }^{2,}$ Dr Deshraj Jain ${ }^{3}$ \\ ${ }^{1}$ Associate Professor Department of Prosthodontics, Government Dental College, Room no. 7, first floor, \\ Sardar Patel Marg, Indore Madhya Pradesh, India. \\ ${ }^{2}$ A-4/ 1104, Saviour Park Loni Road, Mohan Nagar Ghaziabad \\ ${ }^{3}$ Professor and Head Department of Prosthodontics, Government Dental College, Room no. 7, first floor, \\ Sardar Patel Marg, Indore Madhya Pradesh, India
}

\begin{abstract}
It is a challenging endeavour for a prosthodontist to fabricate a maxillofacial prosthesis in cases exhibiting compromised tissue-bed conditions; and more so in an un-cooperative patient, who disbelieves and doubts a "dentist's competence" to make an eye which is traditionally not considered a dentist's area of expertise. This article explains the advantages of custom made ocular prosthesis over stock eye shells and importance of the approach taken by the clinician to find out the actual cause for the un-cooperation of the patient, in order to render an effective and efficient rehabilitative care.
\end{abstract}

Keywords - artificial eye, custom made ocular prosthesis, maxillofacial prosthesis

\section{Introduction}

The disfigurement caused by the loss of an eye can lead to significant physical and emotional behavioural issues.1Most patients experience mental stress and undergo an emotional turmoil, due to societal reactions to the unusual facial features caused by the disability. 2 This leads to social and mental isolation of the patients. The loss of an organ as important as eye, which holds great aesthetic and functional value can cause severe anxiety, stress, and depression at initial stage of the loss. ( Bartlett SO, Moore DJ. Ocular prosthesis: a physiologic system. J Prosthet Dent 1973;29:450-9.

In order to enhance the physical and psychological healing of the patients and to promote their social acceptance, timely replacement of the lost eye is imperative.( Artopoulou I, Montgomery P, Wesley P, Lemon J. Digital imaging in the fabrication of ocular prostheses. The Journal of prosthetic dentistry2006;95(4):32730.)After medical or dental interventions enhance the appearance and function of a patient with craniofacial defects, there has been a profound effect on the individual's overall happiness and productivity.(Prosthodontic and psychological factors in treating patients with congenital and craniofacial defects Alan Joseph Hickey, DMD,a and Margery Salter,(J Prosthet Dent 2006;95:392-6.)

The need for an artificial eye can sometimes be fulfilled by the stock prosthesis which is quite inexpensive and easily available.3However, since every socket differs in size and shape, an individually designed prosthesis (custom-made ocular prosthesis), made from an impression of the socket, is needed to restore the original physiologic contour and form of the eyeball it is supposed to replace.4 Either due to lack of knowledge amongst population regarding a dentist's expertise to fabricate a custom-made prosthesis or the less time consuming "fitting' of stock eyes done at ophthalamic pharmacies which require no expertise whatsoever, the stock eye prostheses, despite being aesthetically and functionally less superior, have been used extensively over the Indian diaspora.This article highlights the difficult task faced by the prosthodontist in convincing the patient to let go of the un-aesthetic and boxy stock prostheses for an aesthetically pleasing and functionally superior custom-made ocular prosthesis and finding out the exact cause of the missing eye.

\section{Case Report}

A 25 year old female presented herself in the Department of Prosthodontics, Government Dental College, Indore, India, for oral rehabilitation of a missing lower left first molar. Her left eye socket was empty as the eye was enucleated three years ago(figure 1 and 2), the reason of which was 'cholera' (as told by the patient during recording of the case history on first appointment.) She was also carrying an ill-fitting and unaesthetic stock ocular prostheses and requested it to be fitted again. She had not worn it for a month as, in her own words, it gave her 'red eye'. Patient's medical history was non-contributory. A detailed clinical and radiographic oral examination was carried out in regard to the dental treatment. After patient's dental rehabilitation was completed, she was approached for ocular rehabilitation. Patient, however, expressed a strong disinterest in letting 'a dentist do something to her already missing eye'.Also, she did not want to look 'unnecessarily pretty'. 
On the subsequent visit, after the patient was shown the aesthetic results achieved in an another patient, who had reported for the follow up for his ocular prosthesis,she reluctantly gave her consent for the custom made ocular prosthesis. As the patient showed traits of being an introvert and subdued nature and had difficulty in communicating, it was decided that a female staff member should be present during the clinical procedures. Ocular impression of the left eye socket was made using a custom impression tray and alginate following Miller technique(Figure 3 and 4). A two piece mould was made followed by the fabrication of a wax conformer using modelling wax. After the ocular contours were well adjusted (Figure 5), iris placement was done using a millimetre grid marking on patient's forehead (Figure 6). Proper color matching was done, taking the reference of the contralateral eye and iris was selected from a pre-available bank of stock eyes.

Wax pattern was flasked and processed using heat polymerizing acrylic resin. Characterization of the sclera was done using floccules of pink and blue threads to emulate veins and the bluish tinge of bulbar conjunctiva; ground shellac powder and pencil colour were used to bring out the basic yellowish white hue of the underlying sclera (Figure 7 and 8) Throughout the clinical procedures, patient was quite apprehensive as to the final outcome. She did not want any drastic improvement in her appearance as she did not want to look 'unnecessarily pretty' and draw unwanted attention. After a lot of attention was given to developing a bond with the patient and making her feel safe, she finally revealed the true cause of the loss of her eye. At the time of trial of final prosthesis, patient said that she had been a victim of domestic violence since last five years. It was during one of the beatings that she sustained a grievous injury which led to the enucleation of the left eyeball.

After the knowledge of any of such incidents, it is incumbent upon the clinician to report in the nearest police station. Patient was explained the seriousness of her situation and was also told to consider the safety and wellbeing of her four year old daughter. Subsequently, she lodged a complaint leading to the arrest of the offender. After a month, she was requested for some photographs with the final prosthesis which she had initially rejected. Now she happily came and was also in a better physical and mental state (Figure 9 and 10).

\section{Case Discusson}

Though the fine art and technique of the fabrication of an ocular prosthesis has been practiced since the ancient times of early Egyptian and Peruvian Indians, but not until the time of second world war and the development of refined plastics, has there been an esthetic ocular prosthesis. The most aesthetic ocular replacement is the custom-built and individually constructed acrylic resin artificial eye. This, however, requires a high aesthetic skill and is time consuming. In the past, because of the greater needs for the artificial eyes and scarce availability of the artists who could aesthetically paint iris, mass production of stock resin acrylic prosthesis was started by commercial optical companies. In order to approximate the superior and inferior fornix, these eyes could be trimmed and fitted accordingly.(ocular prosthesis Robert $\mathrm{b}$ welden and john $\mathrm{v}$ nnranen jpd march 1956 vol6 no 2 pg 272-278)

The credit of development of custom acrylic resin ocular prostheses goes to United States Navy. After an extensive research into various aspects of ocular prosthesis fabrication, it was concluded that each enucleated eye socket was individual in properties and topography. Hence, it is essential to make an exact impression of the area to be restored. $(5,6)$ The custom-made acrylic resin ocular prosthesis provides an intimate adapation between the prosthesis and ocular bed tissues which distributes the pressure more equally than does a stock eye prosthesis. This minimizes the chances of conjunctival abrasion or ulceration. Such prosthesis also improves tissue health by eliminating potential stagnation spaces at the prosthetic-tissue interface. Such fluid collection may cause tissue irritation and bacterial growth. $(7,8,9)$ An ocular prosthesis which has been fabricated after giving detailed attention to the precise duplication of natural size, color and contour will bring about realism and symmetry for the patient.( Fabrication of an ocular prosthesis

Kenneth E. Brown, Commander (DC) USN* jpd aug 1970 vol 24 no 2 pg 225-235) In spite of these advantages, lack of awareness amongst people and consulting a "dentist" for an eye are some factors which are responsible for continued usage of unaesthetic stock eyes. Also, as in this case, patient showed evidence of selfpunishment by not opting for a better looking prosthesis. Freudequates the unconscious need for punishment expressed in forms of self-torment and self-sabotage with an unconscious sense of guilt, present in patient's lives without any actual realisation of presence of that guilt.(Freud, S. (1930). Civilization and its discontents. Standard edition (Vol. 21, pp.59-145).In this case report, a detailed and conversational case history was recorded and a female staff member was asked to take the patient into confidence which led to the revelation of the actual cause of loss of eyes. Thus, a prosthodontist's job is not only limited to mechanically fabricating the prosthesis but also skilfully and sensitively interacting with the patients in order to form an interpersonal relationship, making them more cooperative regarding dental care.(Overcoming the Psychological challenges by prosthetic rehabilitation of a teenage female with ectodermal dysplasia; a clinical report -deshraj jain, Rahul vishnoi,alka gupta IOSR-JDMSVOL 14 issue 8 aug 2015 p 93-97) 


\section{Conclusion}

Importance of recording a detailed case history and maintaining a sympathetic attitude towards the actual needs of the patient cannot be more emphasised upon. Sometimes a clinician has to delve deeper into the psyche of the patient and look beyond just a chief complaint. If the patient, who originally came for the oral rehabilitation, was not made aware of the better prosthetic option for her enucleated eye sockets and was not assured of a better and safe future, she would not have been able to muster up enough confidence to report against the domestic abuse she had been suffering from for years.

\section{References}

[1]. Lubkin V, Sloan S. Enucleation and psychic trauma. Adv Ophthalmic Plast Reconstr Surg 1990;8:259-62.

[2]. Ioli-Ioanna Artopoulou, DDS, MS,a Patricia C. Montgomery,b Peggy J. Wesley, CDA,c and James C. Lemon, DDSd (J Prosthet Dent 2006;95:327-30.)

[3]. Mathew FM, Smith MR, Suttion JA et al (2000) The ocular impression: a review of the literature and presentation of an alternate technique. J Prosthodont 9:210-216

[4]. 4Ocular prosthesis: A physiologic system Stephen O. Bartlett, D.D.S.,* and Dorsey J. Moore, j. Prosthet, Dent. April, 1973

[5]. Pitton RD, Murphey PJ, Schlossberg L, et al: The development of acrylic eye prosthesis at the national naval medical center. J Am Dent Assoc 1945;32:1227-1244

[6]. The Ocular Impression: A Review of the Literature and Presentation of an Alternate Technique Mark F. Mathews, DDS, MS,1 Rick M. Smith, DDS, MS,2 Alan J. Sutton, DDS, MS,3 and Ron Hudson4 J Prosthodont 2000;9:210-216.

[7]. Firtell DN. Ocular implants. Complications. In: Beumer J Ill, Curtis TA, Firtell DN, editors. Maxillofacial rehabilitation: prosthodontic and surgical considerations. St Louis: CV Mosby; 1979. pp. 348-52, 362-4.

[8]. Helland M. Fabrication of ocular prostheses. In: Beumer J II1, Curtis TA, Firtell DN, editors. Maxillofacial rehabilitation: prosthodontic and surgical considerations. St Louis: CV Mosby; 1979. pp. 352-62.

[9]. Ocular prosthetics: Use of a tissue conditioner material to modify a stock ocular prosthesis R. K. K. Ow, BDS, MSc, a and S. Amrith (J Prosthet Dent 1997;78:218-22.)

\section{LEGENDS}

Figure 1 and 2- Initial presentation of the patient with enuleated left eye socket.
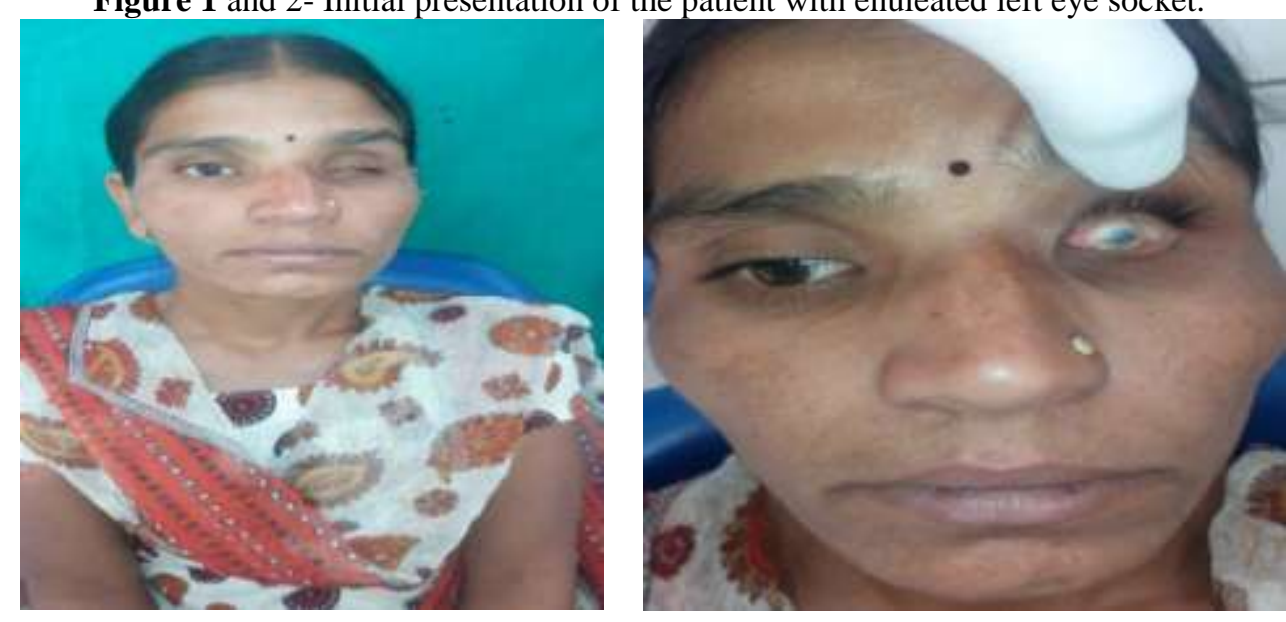

Figure 3 and 4- Custom ocular tray and the ocular impression.

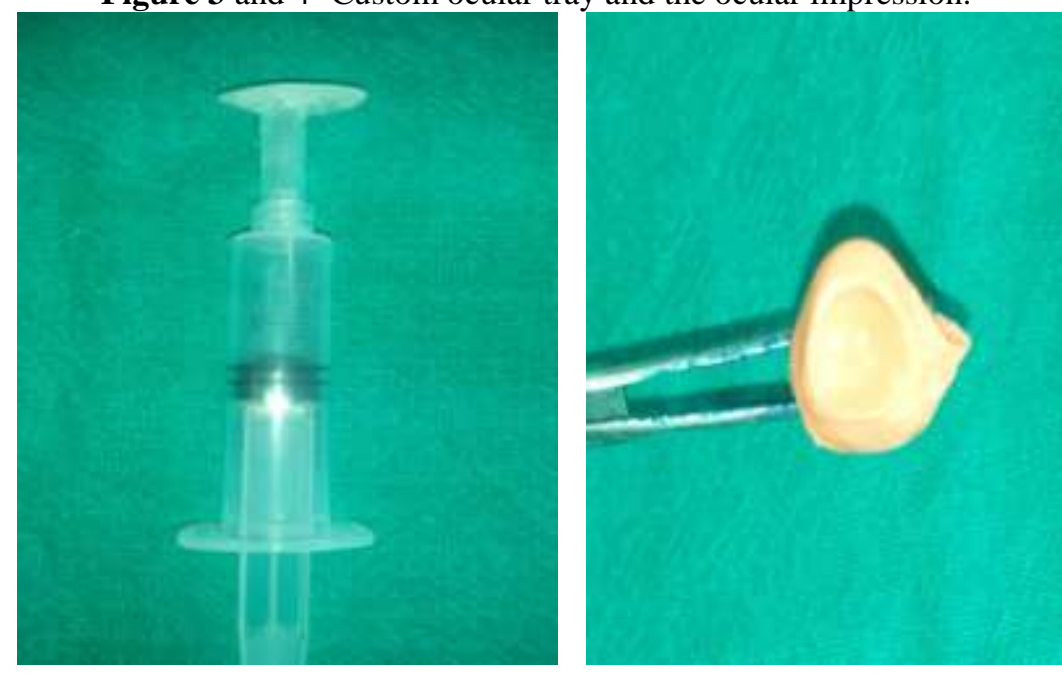


Figure 5- Wax ocular conformor trial.

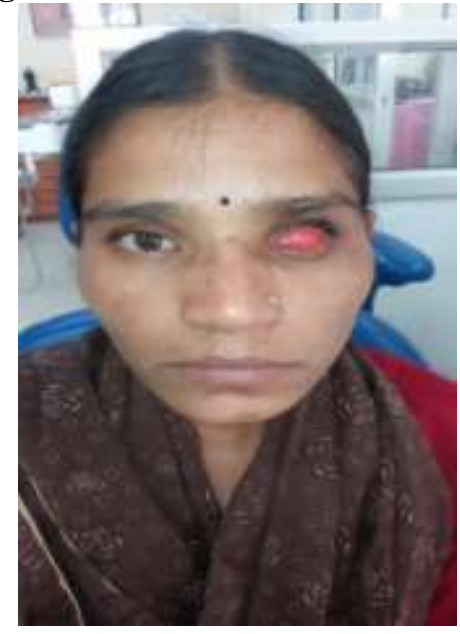

Figure 6- Iris placement using a milimeter grid.

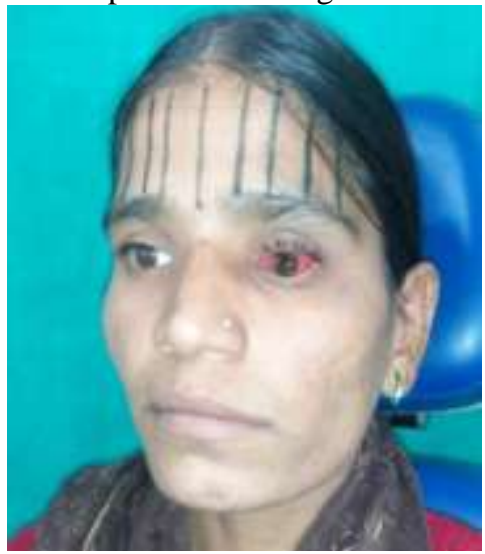

Figure 7 and 8- Materials used for the characterization of the prosthesis.
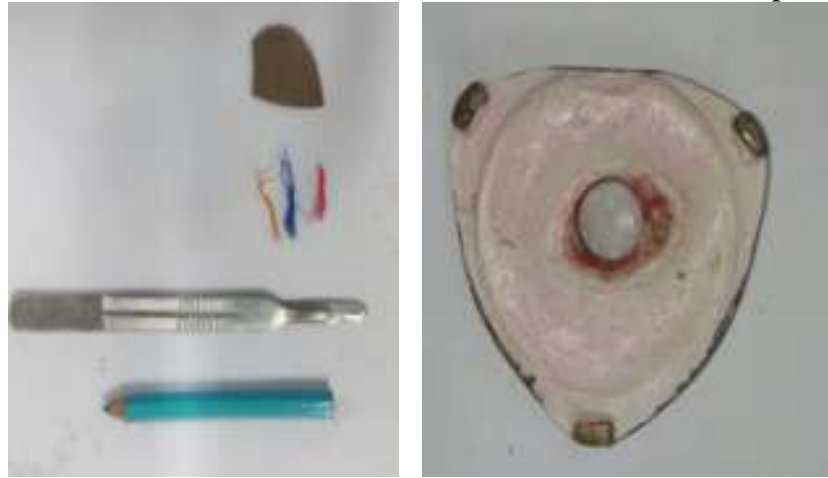

Figure 9 and 10- A satisfied and happy patient wearing the custom-made ocular prosthesis.
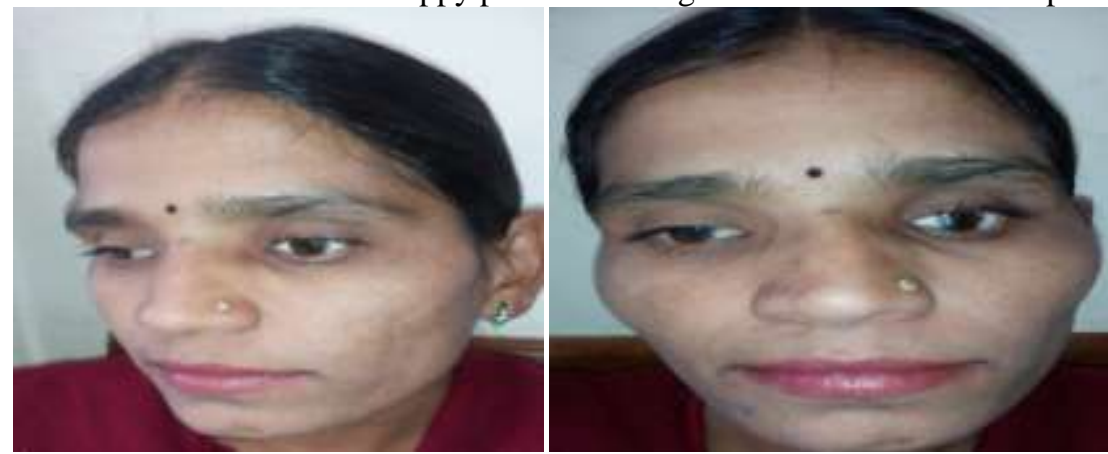